\title{
Modulation of Macrophage Polarization by Viruses: Turning Off/On Host Antiviral Responses
}

\author{
Shaoxiong Yu, Hailiang Ge, Su Li* and Hua-Ji Qiu* \\ State Key Laboratory of Veterinary Biotechnology, National African Swine Fever Para-Reference Laboratory, Harbin \\ Veterinary Research Institute, Chinese Academy of Agricultural Sciences, Harbin, China
}

OPEN ACCESS

Edited by: Chunfu Zheng,

University of Calgary, Canada

Reviewed by:

Yiping Wang,

University of Florida, United States

Jialin Zhang,

University of Missouri, United States

*Correspondence:

Hua-Ji Qiu

qiuhuaji@caas.cn

Su Li

lisu@caas.cn

Specialty section:

This article was submitted to

Virology,

a section of the journal

Frontiers in Microbiology

Received: 20 December 2021

Accepted: 12 January 2022

Published: 11 February 2022

Citation:

Yu S, Ge H, Li S and Qiu H-J (2022) Modulation of Macrophage

Polarization by Viruses: Turning

Off/On Host Antiviral Responses.

Front. Microbiol. 13:839585.

doi: 10.3389/fmicb.2022.839585
Macrophages are professional antigen-presenting cells and serve as the first line of defense against invading pathogens. Macrophages are polarized toward the proinflammatory classical (M1) or anti-inflammatory alternative (M2) phenotype upon viral infections. M1-polarized macrophages exert critical roles in antiviral responses via different mechanisms. Within the long competitive history between viruses and hosts, viruses have evolved various immune evasion strategies, inhibiting macrophage acquisition of an antiviral phenotype, impairing the antiviral responses of activated macrophages, and/or exploiting macrophage phenotypes for efficient replication. This review focuses on the sophisticated regulation of macrophage polarization utilized by viruses and is expected to provide systematic insights into the regulatory mechanisms of macrophage polarization by viruses and further facilitate the design of therapeutic targets for antivirals.

Keywords: macrophages, macrophage polarization, regulation network, antiviral responses, immune evasion

\section{INTRODUCTION}

In the battle against viruses, immune cells, including macrophages, are essential fighters that directly kill viruses or secrete antiviral factors. Macrophages originate from bone marrow-derived monocytes. Upon inflammation, circulating monocytes in peripheral blood migrate into different tissues and are differentiated into several types of macrophages, such as microglia (central nervous system), alveolar macrophages (lung), Kupffer cells (liver), histocytes (spleen), and osteoclasts (bone marrow) (Epelman et al., 2014; Shapouri-Moghaddam et al., 2018).

Macrophages are multifunctional immune cells that exert their functions through phagocytosis, antigen presentation, and cytokine production. Macrophage activation is also known as polarization (Sang et al., 2015). Macrophages can be activated by diverse stimuli and signals and polarized into one of two phenotypes: the classical (M1) and alternative (M2) phenotypes (Murray, 2017; Shapouri-Moghaddam et al., 2018). M1 macrophages are characterized by the release of proinflammatory cytokines, while high-level anti-inflammatory cytokines are produced in M2 macrophages that are involved in tissue remodeling and repair. Macrophages can also be activated and polarized into the M1 or M2 phenotype in response to viral infections. M1polarized macrophages are usually considered antiviral, while M2-polarized macrophages are considered immunosuppressive. Viruses have evolved multiple strategies to counteract the antiviral responses elicited by M1 macrophages and take advantage of M2-polarized macrophages for efficient replication (Sang et al., 2015). 
This review presents an overview of the sophisticated regulation of macrophage polarization and focuses on the multiple immune evasion and exploitation mechanisms leveraged by various viruses against the antiviral responses of polarized macrophages.

\section{MACROPHAGE POLARIZATION IS A DELICATELY REGULATED CELLULAR PROCESS}

\section{Induction of Macrophage Polarization}

Upon stimulation, macrophages are differentiated into two distinct subpopulations, classical or inflammatory M1 macrophages and alternative or anti-inflammatory M2 macrophages (Shapouri-Moghaddam et al., 2018). M1 macrophages differentiation is induced by Th1 cytokines, such as interferon $\gamma($ IFN- $\gamma)$ and interleukin $1 \beta$ (IL-1 $\beta)$, or lipopolysaccharides (LPSs), and these macrophages produce several proinflammatory cytokines, including tumor necrosis factor $\alpha$ (TNF- $\alpha)$, interleukin $1 \alpha$ (IL-1 $\alpha)$, IL-1 $\beta$, IL-6, IL-12, and IL-23. Macrophage polarization into the M1 phenotype results in the increased expression of several marker molecules (such as CD80, CD86, and CD68), major histocompatibility complex class II (MHC-II), and inducible nitric oxide synthase 2 (iNOS2). In contrast, M2 macrophages are usually more sophisticated and are classified into four subtypes depending on the stimuli: M2a, M2b, M2c, and M2d (Wang et al., 2019). M2a macrophages are induced by IL- 4 or IL-13 and characterized by high expression of the CD206 decoy receptor IL-1 receptor 2 (IL-1R2) or arginase 1 (Arg-1) and secretion of cytokines that contribute to tissue repair, such as transforming growth factor $\beta$ (TGF- $\beta$ ) and IL-10. M2b macrophages are stimulated by immune complexes, Toll-like receptor (TLR) ligands or IL-1 $\beta$ and secret proinflammatory and anti-inflammatory cytokines, such as TNF- $\alpha$, IL-1 $\beta$, IL-6, IL-10, and CCL1. M2c macrophages are induced by IL-10, TGF- $\beta$, or glucocorticoids and characterized by the expression of CD163 and CD206 and exhibit anti-inflammatory activities by producing IL-10 and TGF- $\beta$. M $2 \mathrm{~d}$ macrophages are activated by TLR ligands and adenosine receptor ligands and characterized by the production of IL-10 and VEGF, which promote angiogenesis and tumor progression.

\section{Signaling Pathways in the Regulation of Macrophage Polarization}

Macrophages are regulated by diverse coordinated signaling pathways, differentiated into the M1 or M2 phenotype, and exert multiple functions. The nuclear factor kappa B $(\mathrm{NF}-\kappa \mathrm{B})$, Janus kinase/signal transducer and activator of transcription (JAK-STAT), mitogen-activated protein kinase (MAPK), and Notch signaling pathways are involved in macrophage polarization (Figure 1).

\section{Nuclear Factor Kappa B Signaling Pathway}

$\mathrm{NF}-\kappa \mathrm{B}$ is an important transcription factor involved in the production of proinflammatory cytokines. The NF- $\kappa$ B signaling pathway is activated by TLRs (such as TLR4) or cytokine receptors [such as the IL-1 receptor (IL-1R)] in response to their ligands (LPSs and IL-1, respectively), resulting in the activation of the IкB kinase (IKK) complex (Liu et al., 2014; Dorrington and Fraser, 2019). Then, IКB $\alpha$ is phosphorylated by the activated IKK complex and quickly undergoes ubiquitination followed by proteasomal degradation (Mulero et al., 2019). The NF- $\kappa$ B dimers p50/p65 are released from $\mathrm{I} \kappa \mathrm{B} \alpha$, are translocated into the nucleus and initiate the production of inflammatory cytokines, such as IL$1 \beta$, IL- 6 , and TNF- $\alpha$, which result in M1 macrophage polarization (Biswas and Lewis, 2010).

\section{Janus Kinase/Signal Transducer and Activator of Transcription Signaling Pathway}

The JAK-STAT signaling pathway is involved in both M1 and M2 macrophage polarization. IFN- $\gamma$ interacts with the IFN- $\gamma$ receptor (IFN- $\gamma \mathrm{R}$ ), activates the receptor-associated tyrosine kinases JAK1 and JAK2, and subsequently promotes the phosphorylation and dimerization of STAT1 (Ivashkiv, 2018). Activated STAT1 homodimers are translocated into the nucleus, bind to the IFN- $\gamma$-activation sites (GASs), and induce the transcription of interferon-stimulated genes (ISGs), MHC molecules, chemokines, and antiviral factors, promoting macrophage polarization toward the M1 phenotype. In contrast, STAT3 or STAT6 homodimers are translocated into the nucleus in response to IL-4 or IL-13 treatment, resulting in the transcription of the genes encoding M2 phenotype-related antiinflammatory cytokines, such as TGF- $\beta$ and IL-10. In addition, suppressor of cytokine signaling 1 (SOCS1) and SOCS3 block the activation of the STAT1- and STAT3-mediated signaling pathways, respectively.

\section{Mitogen-Activated Protein Kinase Signaling Pathway}

In addition to the NF- $\kappa$ B signaling pathway, the MAPK signaling pathway is also crucial to proinflammatory cytokine production (Arthur and Ley, 2013). The activation of MAPK by TLRs is a well-characterized signaling pathway. Following the activation of TLR4 by its cognate ligands, the signals are transduced through the cytoplasmic Toll and IL-1 receptor (TIR) domain, recruiting myeloid differentiation primary response protein 88 (MYD88) with the requirement of MYD88 adaptor-like protein (TIRAP). IL-1 receptor-associated kinase 4 (IRAK4) interacts with MYD88 and induces the formation of a complex comprised of IRAK1, IRAK2, and TNF receptor-associated factor 6 (TRAF6). Then, TRAF6 undergoes self-ubiquitination by E2 ubiquitin-conjugating enzyme 13 (UBC13) through K63-linked ubiquitin chains. Following the recruitment of TGF- $\beta$-activated kinase 1 (TAK1) to TRAF6 by TAK1-binding protein 2 (TAB2) and TAB3, p38 $\alpha$ and Jun N-terminal kinase (JNK) are activated and induce the expression of proinflammatory cytokines, promoting M1 macrophage polarization (Yang et al., 2014).

\section{Notch Signaling Pathway}

The Notch signaling pathway can promote macrophage differentiation into the M1 phenotype and contribute to the expression of proinflammatory cytokines (Castro et al., 2021; 


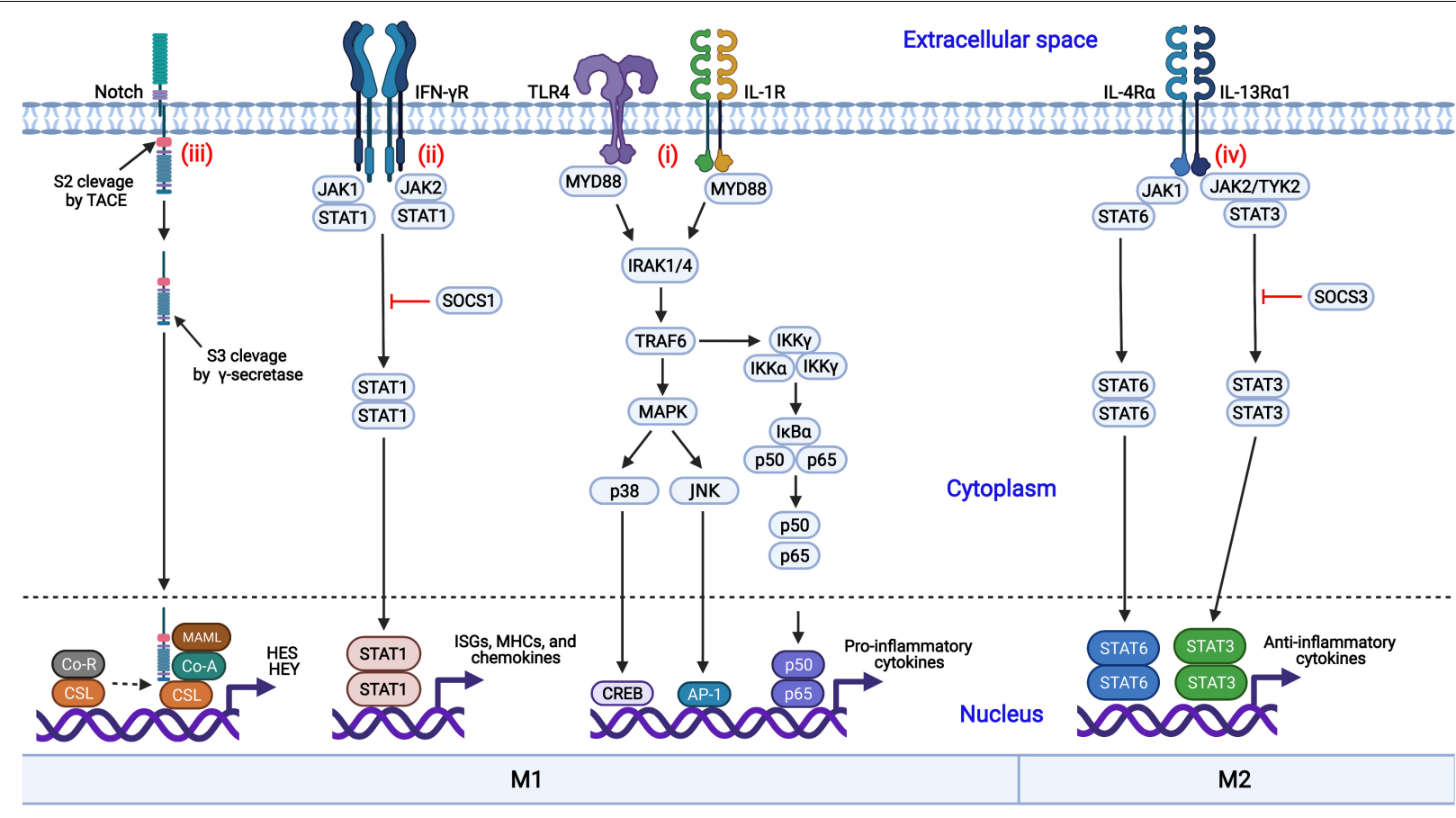

FIGURE 1 | Coordinated regulation of macrophage polarization via multiple signaling pathways. (i) Engagement of TLR4 or IL-1R with the ligands results in the activation of the MAPK and NF-KB signaling pathways and induces the nuclear translocation of several transcription factors, promoting the production of proinflammatory cytokines; (ii) IFN- $\gamma$ binds to its receptor, IFN- $\gamma \mathrm{R}$, and triggers the phosphorylation and dimerization of STAT1, initiating the transcription of IFN-stimulated genes (ISGs); (iii) The interactions of Notch proteins with Delta-like ligands and Jagged ligands induce the activation and nuclear translocation of the Notch intracellular domain (NICD), driving the production of proinflammatory cytokines; (iv) IL-4 or IL-13 binds to its corresponding receptor and triggers the activation of STAT3 or STAT6, respectively, inducing the transcription of anti-inflammatory cytokines and skewing macrophages to the anti-inflammatory M2 phenotype.

Chen et al., 2021). Notch proteins are proteolytically cleaved by furin-like proteinase at cleavage site 1 (S1) and processed into the mature form. Notch proteins consist of the Notch extracellular domain (NECD), the Notch intracellular domain (NICD), and a transmembrane domain. The interactions between the Notch proteins with Delta-like ligands (DLL1, DLL3, and DLL4) and the Jagged family (Jagged 1 and Jagged 2) induce the conformational changes in the receptors and initiate the Notch signaling pathway. Subsequent exposure to cleavage site 2 (S2) promotes proteolytic action by a tumor necrosis factor- $\alpha$-convening enzyme (TACE), a member of the disintegrin and metalloprotease (ADAM) family, and the extracellular domain is released and taken in by adjacent cell with the ligand. Following cleavage by $\gamma$-secretase at $S 3$, the intracellular NICD is activated and translocated into the nucleus. The activated NICD binds to the nuclear transcription factor CSL and dissociates from co-inhibitory receptors, promoting the transcription of the hairy and enhancer of split (HES) and hairy and enhancer of split-related with YRPW motif (HEY) family members and the inhibition of M2 macrophage polarization (Lin et al., 2018).

\section{Regulation of Macrophage Polarization by Inhibitory Receptors}

In addition to regulation by sophisticated signaling pathways, several inhibitory receptors are also involved in the polarization of macrophages (Figure 2).

\section{Programmed Cell Death 1}

Programmed cell death 1 (PD-1, also called CD279) is an inhibitory receptor and mainly expressed on immune cells, such as activated $\mathrm{T}$ and $\mathrm{B}$ lymphocytes, natural killer (NK) cells, dendritic cells (DCs), and macrophages (Cai et al., 2019). PD-1 is well studied in T lymphocytes. The interaction of PD-1 and its ligand PD-ligand 1 (PD-L1, also called B7-H1 or CD274) delivers negative regulatory signals and inhibits $\mathrm{T}$ cell activation through targeting the PI3K-Akt and Ras-MEK-ERK pathways (Boussiotis, 2016). Moreover, PD-1 plays a vital role in the function and phenotype of macrophages. PD-1 suppresses M1 polarization by decreasing the phosphorylation of STAT1 and promotes M2 polarization through increasing the phosphorylation of STAT6, which in turn reduces the expression of IL-12 (Ma et al., 2011; Yao et al., 2014).

\section{T Cell Immunoglobulin and Mucin Domain-Containing Protein 3}

$\mathrm{T}$ cell immunoglobulin and mucin domain-containing protein 3 (TIM3) was initially identified as a marker molecule on $\mathrm{CD}^{+}$and $\mathrm{CD}^{+} \mathrm{T}$ cells producing IFN- $\gamma$ (Wolf et al., 2020). Subsequently, DCs, NK cells, macrophages, and mast cells were also shown to express TIM3 (Zhao et al., 2020). TIM3 consists of four distinct domains: a variable immunoglobulin domain ( $\mathrm{IgV})$, a mucin domain, a transmembrane domain, and an intracellular region (Ocaña-Guzman et al., 2016). TIM3 interacts with its 


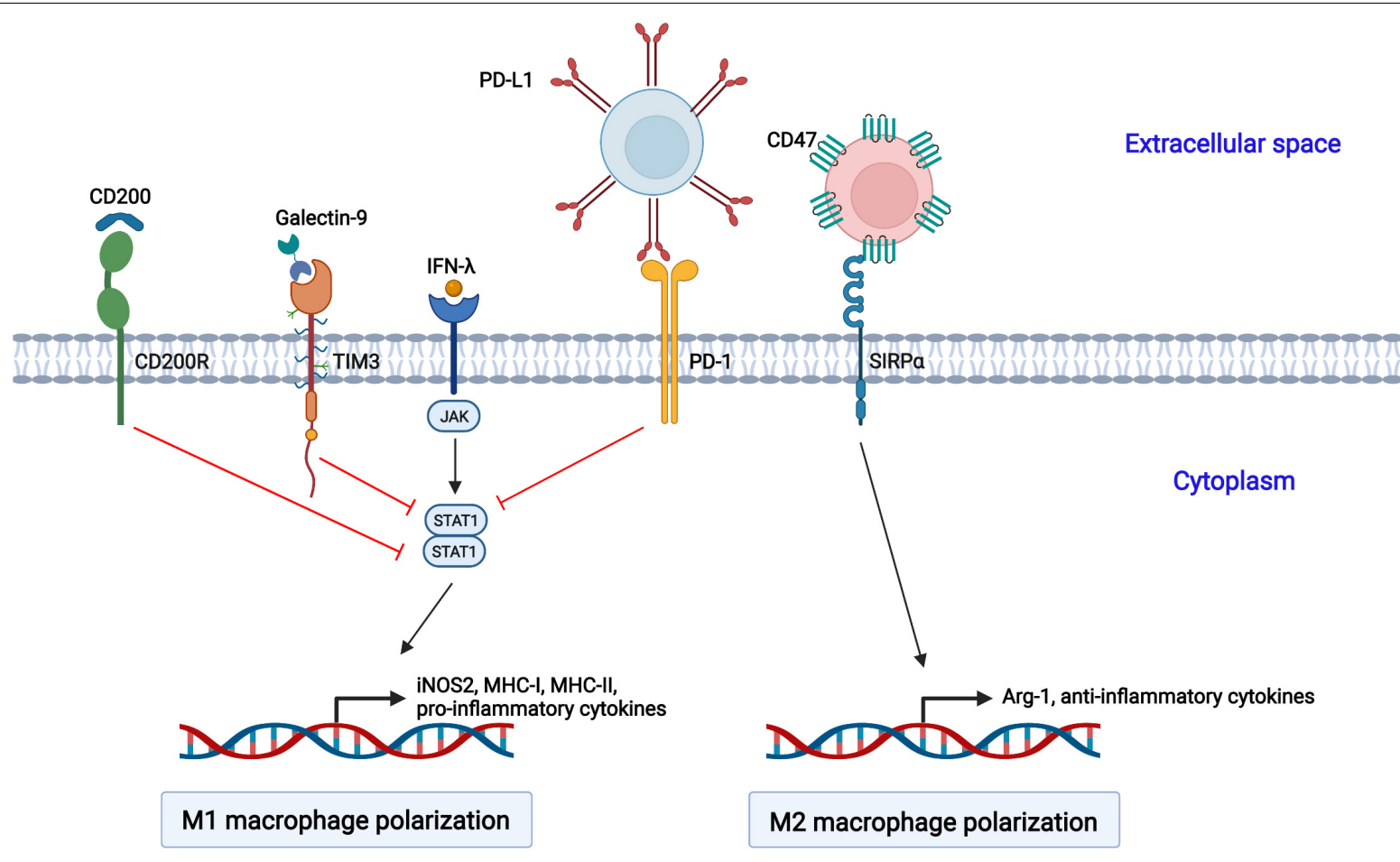

FIGURE 2 | Negative regulation of macrophage polarization by cellular inhibitory receptors. The activation of CD200R, TIM3, and PD-1 suppresses STAT1-mediated macrophage polarization toward the M1 phenotype. CD47 interacts with SIRP $\alpha$ on the cell surface of macrophages and promotes macrophage polarization toward the M2 phenotype.

ligand galectin-9, which leads to the phosphorylation of the intracellular tail by the Src and Tec family kinases, reducing the phosphorylation of STAT1 but augmenting that of STAT3. The activated TIM3/galectin-9 signaling pathway inhibits the LPSsmediated polarization of macrophages toward the M1 phenotype (Zhang W. et al., 2019).

\section{CD200 Receptor}

The CD200 receptor (CD200R) belongs to the immunoglobulin superfamily of the mainly expressed on $\mathrm{T}$ cells and myeloid cells, and it contains one $\mathrm{NH}_{2}$-terminal extracellular domain, one transmembrane domain, and a short C-terminal intracytoplasmic domain (Ocaña-Guzman et al., 2018; Kotwica-Mojzych et al., 2021). The interaction of CD200R with its ligand CD200 results in the phosphorylation of tyrosine residues in the intracellular tail of CD200R by Src family kinases. Subsequently, Dok2 is recruited and binds to the phosphorylated tyrosine residues, and Ras-specific GTPase-activating protein (RasGAP) is further recruited to Dok2, inducing the inhibition of the Ras-ERK and PI3K kinases and the activation of STAT1.

\section{CD47}

CD47 is a member of the immunoglobulin superfamily (IgSF) and is widely expressed on hematopoietic and non-hematopoietic cells (Hayat et al., 2020). It contains a single N-terminal extracellular IgV domain, five transmembrane helices, and a C-terminal cytoplasmic tail. CD47 interacts with signal regulatory protein alpha $(\operatorname{SIRP} \alpha)$ on macrophages, causes the tyrosine phosphorylation of SIRP $\alpha$, and promotes the interaction with the phosphatase SHP-1, resulting in the transduction of "Don't eat me" signals to macrophages and the induction of macrophage polarization into the M2 phenotype (Murata et al., 2014; Lin et al., 2018). CD47 is the best studied in antitumor treatment, and anti-CD47 antibody-based therapies targeting the CD47-SIRP $\alpha$ axis enhance the phagocytosis of cancer cells by macrophages (Zhang W. et al., 2020).

\section{Involvement of Cell Metabolism in Macrophage Polarization}

Macrophage polarization is also coordinately regulated by metabolic networks, such as glucose, lipids, amino acids, and iron metabolism, described as "immunometabolism" (Van den Bossche et al., 2017; Yan and Horng, 2020; Xia et al., 2021). Glucose is principally metabolized through glycolysis, the pentose phosphate pathway (PPP), and the Krebs cycle (tricarboxylic acid cycle, TCA cycle) (Zhang Q. et al., 2021). Glucose metabolism may play an essential role in macrophage polarization. M1 macrophages are characterized by a high rate of glycolysis, and glycolysis produces adenosine triphosphate (ATP) and supplies glucose-6-phosphate to the PPP, promoting the generation of intermediates for amino acids, ribose, and NADPH that are required by inflammatory macrophages. In addition, the enzymes required for glycolysis promote proinflammatory M1-type macrophages (Van den Bossche et al., 2017). For instance, hexokinase 1 (HK1) positively regulates the NLRP3 
inflammasome activation to produce IL-1 $\beta$. In M2-polarized macrophages, oxidative phosphorylation (OXPHOS) and fatty acid oxidation (FAO) are increased to produce additional ATP, supporting the functions of these anti-inflammatory macrophages, such as tissue repair.

\section{VIRAL INFECTIONS INDUCE MACROPHAGE POLARIZATION}

Macrophages are polarized into different phenotypes upon viral infections (Table 1). Some viruses induce macrophage polarization toward the M1 phenotype, while others promote M2 polarization. Moreover, several viruses cause complex polarization of macrophages depending on viral strains, infection stages, and gender of the host. Virus-infected macrophages are usually polarized into the proinflammatory M1 and antiinflammatory M2 phenotypes in the early and late stages of infection, respectively (Burdo et al., 2015). Generally, pathogenic virus strains inhibit the antiviral responses of M1-polarized macrophages and skew macrophage polarization toward the M2 phenotype, whereas attenuated virus strains induce the M2 phenotype (Ferrer et al., 2019). The susceptibility of macrophages to different subtypes of influenza viruses (IVs) varies, and most of the H5N1 subtype highly pathogenic avian influenza viruses (HPAIVs) isolates can productively infect macrophages and induce M1 polarization (Marvin et al., 2017). Therefore, these studies suggests that the induction of M1 macrophage polarization is involved in clearance of invading viruses, but the severe injuries can be caused by hyperactivation or persistent activation characterized by robust proinflammatory cytokines. Therefore, the infections of virulent viruses usually results in illness or even death of hosts.

\section{M1-POLARIZED MACROPHAGES COMBAT VIRAL INFECTION THROUGH MULTIPLE ANTIVIRAL STRATEGIES}

Activated macrophages, mainly M1-polarized macrophages, play essential roles in fighting against viral infections through multiple strategies, including producing an oxidized environment and antiviral cytokines or activating other immune cells.

\section{Production of Reactive Species}

Reactive species (RS) produced in M1 macrophages include reactive oxygen species (ROS) and reactive nitrogen species (RNS), which lead to a highly oxidative environment (Molteni et al., 2014; Camini et al., 2017). ROS, mainly hydrogen peroxide $\left(\mathrm{H}_{2} \mathrm{O}_{2}\right)$, superoxide anions $\left(\cdot \mathrm{O}_{2}-\right)$, and hydroxyl radicals $(\cdot \mathrm{OH})$, are generated by mitochondria, NADPH oxidase (NOX), endoplasmic reticulum (ER), and/or peroxisomes (Rendra et al., 2019). Furthermore, nitric oxide (NO) is the most important RNS in macrophages and is synthesized through the conversion of L-arginine by iNOS2 (Uehara et al., 2015). NO exerts potent antimicrobial activity with a broad spectrum via different mechanisms. NO suppresses vaccinia virus (VACV)
TABLE 1 | Summarization of virus-induced macrophage polarization.

\begin{tabular}{|c|c|c|c|c|}
\hline Virus & Family & $\begin{array}{l}\text { Viral genome } \\
\text { type }\end{array}$ & $\begin{array}{c}\text { Polarized } \\
\text { phenotype }\end{array}$ & References \\
\hline Junin virus (JUNV) & Arenaviridae & -ssRNA & $\begin{array}{c}\text { Attenuated } \\
\text { Candid } 1 \text { strain: } \\
\text { M1; Pathogenic } \\
\text { P strain: M2 }\end{array}$ & $\begin{array}{l}\text { Ferrer et al., } \\
2019\end{array}$ \\
\hline Influenza virus (IV) & Orthomyxoviridae & $\begin{array}{l}\text { Segmented } \\
\text {-ssRNA }\end{array}$ & M1 & $\begin{array}{c}\text { Zhang et al., } \\
2018\end{array}$ \\
\hline $\begin{array}{l}\text { Severe fever with } \\
\text { thrombocytopenia } \\
\text { syndrome virus } \\
\text { (SFTSV) }\end{array}$ & Bunyaviridae & $\begin{array}{l}\text { Segmented } \\
\text {-ssRNA }\end{array}$ & M2 & $\begin{array}{l}\text { Zhang L. et al., } \\
2019\end{array}$ \\
\hline $\begin{array}{l}\text { Foot-and-mouth } \\
\text { disease virus } \\
\text { (FMDV) }\end{array}$ & Picornaviridae & +SsRNA & M1 & $\begin{array}{l}\text { Sebastian } \\
\text { et al., } 2020\end{array}$ \\
\hline $\begin{array}{l}\text { Coxsackievirus B3 } \\
\text { (CVB3) }\end{array}$ & Picornaviridae & +SsRNA & $\begin{array}{c}\text { Male: M1; } \\
\text { Female: M2 }\end{array}$ & Li et al., 2009 \\
\hline $\begin{array}{l}\text { Porcine } \\
\text { reproductive and } \\
\text { respiratory } \\
\text { syndrome virus } \\
\text { (PRRSV) }\end{array}$ & Arteriviridae & +SsRNA & M2 & $\begin{array}{l}\text { Wang et al., } \\
2017\end{array}$ \\
\hline $\begin{array}{l}\text { West Nile virus } \\
\text { (WNV) }\end{array}$ & Flaviviridae & +ssRNA & M1 & $\begin{array}{l}\text { Stone et al., } \\
2019\end{array}$ \\
\hline $\begin{array}{l}\text { Hepatitis C virus } \\
(\mathrm{HCV})\end{array}$ & Flaviviridae & +SSRNA & M2 & $\begin{array}{c}\text { Bility et al., } \\
2016\end{array}$ \\
\hline $\begin{array}{l}\text { Severe acute } \\
\text { respiratory } \\
\text { syndrome } \\
\text { coronavirus } 2 \\
\text { (SARS-CoV-2) }\end{array}$ & Coronaviridae & +SsRNA & M2 & $\begin{array}{c}\text { Boumaza et al., } \\
2021\end{array}$ \\
\hline $\begin{array}{l}\text { Human } \\
\text { immunodeficiency } \\
\text { virus type } 1 \text { (HIV-1) }\end{array}$ & Retroviridae & +SsRNA & $\begin{array}{c}\text { Acute phase: } \\
\text { M1; Chronic } \\
\text { phase: M2 }\end{array}$ & $\begin{array}{l}\text { Burdo et al., } \\
2015\end{array}$ \\
\hline $\begin{array}{l}\text { Hepatitis B virus } \\
\text { (HBV) }\end{array}$ & Hepadnaviridae & cccDNA & M2 & $\begin{array}{c}\text { Bility et al., } \\
2014\end{array}$ \\
\hline $\begin{array}{l}\text { Epstein-Barr virus } \\
\text { (EBV) }\end{array}$ & Herpesviridae & dsDNA & M2 & $\begin{array}{c}\text { Zhang B. et al., } \\
2020\end{array}$ \\
\hline $\begin{array}{l}\text { Human } \\
\text { cytomegalovirus } \\
\text { (HCMV) }\end{array}$ & Herpesviridae & dsDNA & M1 & $\begin{array}{c}\text { Chan et al., } \\
2008\end{array}$ \\
\hline $\begin{array}{l}\text { African swine fever } \\
\text { virus (ASFV) }\end{array}$ & Asfarviridae & dsDNA & M1 & $\begin{array}{c}\text { Tatoyan et al., } \\
2020\end{array}$ \\
\hline
\end{tabular}

replication by impairing viral ribonucleotide reductase activity (Fujikura et al., 2009). Similarly, NO exerts an inhibitory effect on severe acute respiratory syndrome coronavirus 2 (SARS-CoV-2) replication by targeting the activity of the 3CL protease (Akaberi et al., 2020). Clinically, inhaled NO has been demonstrated to be an effective therapeutic agent against SARS-CoV-2 infection and severe pulmonary consequences (Adusumilli et al., 2020; Ricciardolo et al., 2020). However, the expression level of iNOS2 varies in macrophages of different species, resulting in differences in NO production (Schneemann and Schoedon, 2002; Zelnickova et al., 2008). Rat pulmonary alveolar macrophages (PAMs) produce a large amount of NO, and bovine PAMs produce a relatively low level of $\mathrm{NO}$ using L-arginine as substrate, while caprine, lapine, and porcine PAMs do not produce NO. Thus, NO may be a potential host range factor that restricts crossspecies transmission. 


\section{Secretion of Antiviral Cytokines}

M1 macrophages are characterized by the robust production of proinflammatory cytokines, such as TNF- $\alpha$, IL-1, IL-6, IL-8, and IL-12, which exert antiviral activities directly or indirectly (Arango Duque and Descoteaux, 2014). The replication of influenza A virus (IAV), human immunodeficiency virus type 1 (HIV-1), porcine respiratory and reproductive syndrome virus (PRRSV), classical swine fever virus (CSFV), and mouse adenovirus is inhibited by the direct treatment of cells with TNF- $\alpha$ (Van Campen, 1994; Lane et al., 1999; Li et al., 2015; Li et al., 2016; Pant et al., 2020). The mechanisms by which TNF- $\alpha$ suppresses viral infections may vary in different viruses. TNF- $\alpha$ exhibits an inhibitory effect on HIV1 by inducing the production of RANTES and decreasing the expression of the $\mathrm{C}-\mathrm{C}$ chemokine receptor (CCR5), which can serve as a co-receptor for HIV-1 entry (Lane et al., 1999). Moreover, TNF- $\alpha$ inhibits CSFV replication through the NF- $\mathrm{BB}$ signaling pathway and the induction of IRF1dependent type I IFN responses (Liniger et al., 2021). IL-6 exhibits potent antiviral effects on hepatitis B virus (HBV) and varicella-zoster virus replication (Kuo et al., 2009; Como et al., 2018). Mechanistically, IL-6 inhibits HBV infection through preventing the formation of genome-containing nucleocapsids and accumulation of the HBV cccDNA. In contrast, antiviral activity of IL-8 is rarely documented, which exhibits an inhibitory effect on HIV-1 replication through suppression of viral transcription (Csoma et al., 2006). IL-1 $\beta$ synergizes with IFN- $\alpha$ to suppress HCV replication by negatively regulating ERK activation (Guo et al., 2020). In addition, IL-12 promotes the differentiation of naïve $\mathrm{CD} 4^{+} \mathrm{T}$ cells into Th1 cells and activates NK cells to fight against the viral infections (Wang et al., 2012).

\section{Activating Other Immune Cells}

In M1-polarized macrophages, B7 family molecules (including CD80 and 86) and MHC molecules are expressed at relatively high levels, which is required for $\mathrm{T}$ cell activation and downstream antiviral responses (Guerriero, 2019). In addition, macrophage-derived cytokines, including IL-2 and IL-12, promote the further activation of $\mathrm{T}$ cells and corresponding antiviral responses. NK cells also play an essential role in antiviral immune responses by secreting of perforin or inducing of death receptor-mediated apoptosis (Zwirner et al., 2021). M1 macrophages, but not M2 macrophages, enhance the cytotoxicity of NK cells in an IL-1 $\beta$-, IFN- $\beta$-, or IL-15-dependent fashion (Mattiola et al., 2015).

\section{MACROPHAGES ARE EXPLOITED AS EFFICIENT VEHICLES FOR VIRAL REPLICATION AND DISSEMINATION}

The host cells with a high susceptibility to viral infections usually have a sufficient lifespan without apoptosis or robust antiviral responses. However, macrophages do not possess these characteristics. Many viruses still exploit macrophages as vehicles for efficient infection (Nikitina et al., 2018). In addition to the pivotal roles in the regulatory network of immune cells, macrophages promote viral infections at entry stage, deliver viruses to permissive tissues and provide an immunofavorable microenvironment.

\section{Promoting Efficient Viral Infection at Entry Stage}

Macrophages are the first line of defense against viral invasion, increasing the possibility of exposure to viruses (Mercer and Greber, 2013). In addition, macrophages are professional antigen-presenting cells (APCs) that constitutively undergo macropinocytosis and phagocytosis. Thus, in addition to receptor-mediated endocytosis, viruses can be captured passively, facilitating viral entry into the cells through multiple routes. African swine fever virus (ASFV) is a large DNA virus that primarily infects macrophages (Gaudreault et al., 2020; Masujin et al., 2021). ASFV hijacks both clathrinmediated endocytosis and macropinocytosis to invade macrophages, and the exploitation of multiple endocytic routes markedly increases the efficiency of ASFV entry (Sánchez et al., 2017).

\section{Delivering Viruses to Permissive Tissues/Organs}

Macrophages circulate in almost all tissues in the bloodstream and are differentiated into tissue-resident macrophages, executing tissue-specific functions. Therefore, viruses in macrophages are delivered to the permissive tissues, promoting further viral infection. Moreover, macrophages interact with different cell populations, and thus viruses can be disseminated through direct cell-to-cell contact (Nikitina et al., 2018).

\section{Providing a Suitable Extracellular Microenvironment}

Due to the essential roles of macrophages in regulating the activity of other immune cells (such as $\mathrm{T}$ cells and NK cells), as described in section "Activating Other Immune Cells," viruses may evolve to exploit macrophages as their main target cells and suppress the direct and indirect antiviral effects from mainly $\mathrm{T}$ cells and NK cells by negatively regulating macrophage polarization, thus promoting viral infections in an immunofavorable microenvironment.

\section{VIRUSES HAVE EVOLVED MULTIPLE STRATEGIES TO COUNTERACT M1 PHENOTYPE MACROPHAGES}

Viruses have evolved diverse strategies to evade the antiviral responses of M1-polarized macrophages to achieve a suitable cellular environment for replication in macrophages, including inhibition of M1 macrophage polarization or antagonization of downstream antiviral responses (Figure 3). 


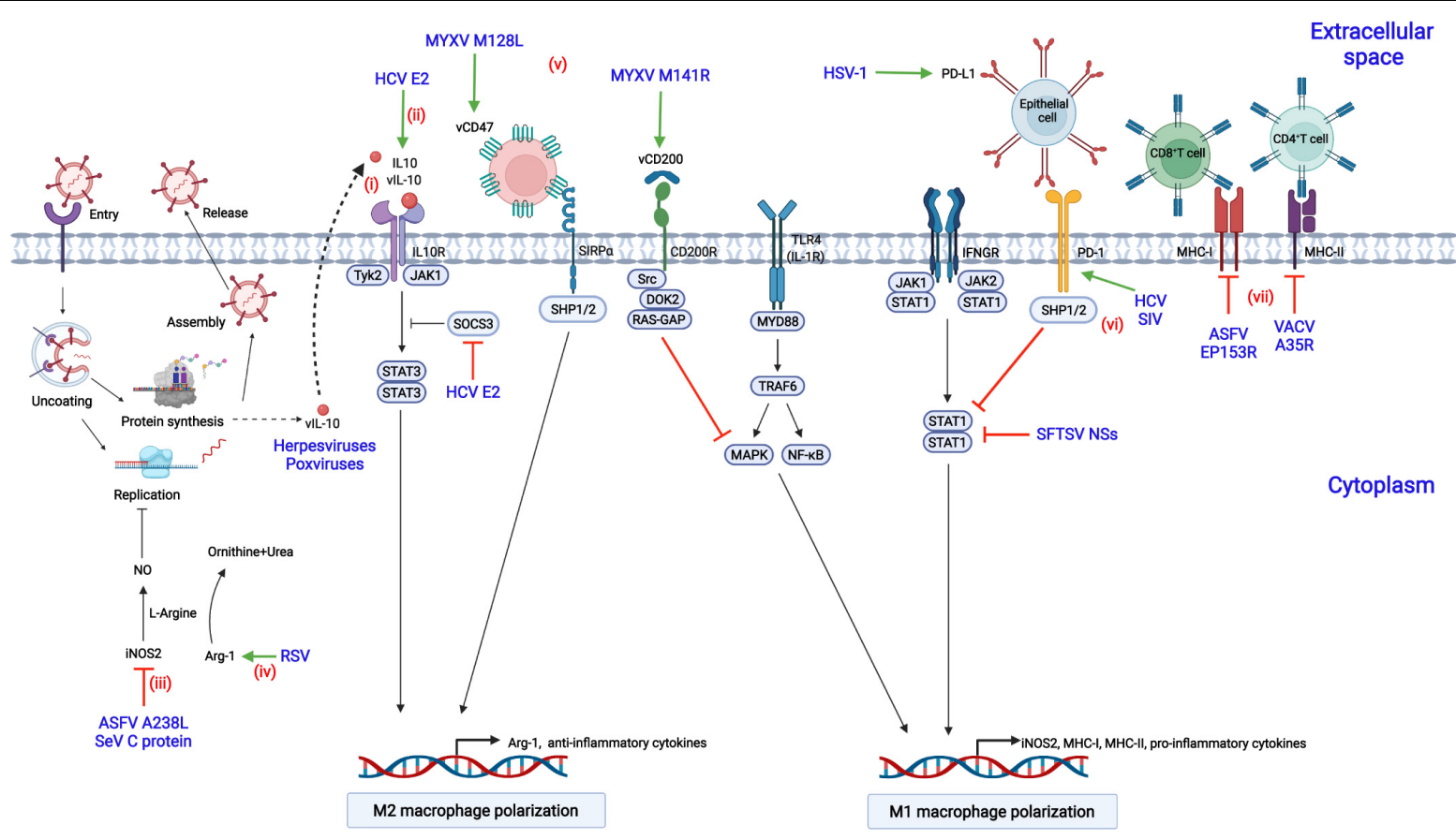

FIGURE 3 | Modulation of macrophage polarization by viral proteins. (i) Herpesviruses or poxviruses encode the homolog of IL-10 (vIL-10), which binds to IL-10R, triggers the activation of STAT3, and contributes to M2 macrophage polarization; (ii) Hepatitis C virus (HCV) encodes the E2 protein, which upregulates IL-10 production by increasing the phosphorylation of STAT3 and reducing the expression of SOCS3; (iii) African swine fever virus (ASFV) infection results in the suppression of nitrogen oxide (NO) production by downregulating inducible nitric oxide synthase 2 (iNOS2) via the A238L protein; (iv) Respiratory syncytial virus (RSV) inhibits NO production by decreasing the expression of arginase 1 (Arg-1) and the level of L-arginine; (v) Myxoma virus (MYXV) encodes the M141R (the viral CD200 homolog) and M128L (the viral CD47 homolog) proteins, which suppress the M1 phenotype polarization of macrophages; (vi) Acute infection with herpes simplex virus type 1 (HSV-1) and chronic infection with HCV or simian immunodeficiency virus (SIV) lead to the increased expression of PD-L1 or PD-1, inhibiting STAT1 activation and M1 macrophage polarization; (vii) The vaccinia virus (VACV) A35R protein suppresses the antiviral responses of T cells by negatively regulating the major histocompatibility complex class II (MHC-II) antigen presentation, while the ASFV EP153R and the HIV-1 Nef proteins downregulate MHC-I expression.

\section{Induction of Macrophage Polarization to the M2 Phenotype by Regulating the Activity of Inhibitory Receptors}

Viral infection promotes macrophage polarization toward the M2 phenotype by increasing the expression of cellular or viral inhibitory receptors, including PD-1, PD-L1, and the viral homologs of CD200 and CD47.

\section{Programmed Cell Death 1 and Its Ligand PD-L1}

In chronic HCV infection, the expression of PD-1 is upregulated, and the production of IL-12 and the activation of STAT1 are suppressed in macrophages (Ma et al., 2011). Similarly, in chronic HIV or Simian immunodeficiency virus (SIV) infection of rhesus macaques, the expression of PD-1 is increased in alveolar macrophages, and the expression of proinflammatory cytokines is dramatically decreased compared with that in naïve macaques, suggesting that M2 polarization are promoted (Burdo et al., 2015; Hunegnaw et al., 2019). PD-L1 is constitutively expressed in the corneal epithelium and is up-regulated upon herpesvirus type 1 (HSV-1) infection (Jeon et al., 2018). Knockout of PD-L1 increases the migration of inflammatory cells into viral lesions and decreases virus titers due to the impaired viral clearance by macrophages.

\section{Viral CD200 Homolog}

Myxoma virus (MYXV) encodes the M141R gene, a homolog of CD200. It interacts with CD200R and inhibits M1 macrophage polarization in an NF- $\mathrm{B}$-dependent fashion (Zhang et al., 2009). Although M141R is not essential for MYXV replication in macrophages, the M141R-deletion MYXV mutant is highly attenuated in rabbits with high-level IFN- $\gamma$, suggesting that M141R affects virus pathogenicity by skewing macrophage polarization toward the M2 phenotype (Cameron et al., 2005). Similarly, human herpesvirus 8 (HHV-8) encodes the K14 protein, similar to CD200, and may skew macrophage polarization toward the M2 phenotype by interacting with CD200R (Foster-Cuevas et al., 2004).

\section{Viral CD47 Homolog}

The M128L gene, encoded by MYXV, is a five-span transmembrane protein similar to CD47. M128L is not essential for viral replication in vitro, but the M128L genedeleted virus is significantly attenuated in rabbits, suggesting that CD47-like M128L is a virulence factor of MYXV (Cameron et al., 2005). Mechanistically, the knockout of M128L from the viral genome may contribute to M1 macrophage polarization, increasing the expression level of iNOS2 and mounting robust antiviral responses. 


\section{Interference With Macrophage Polarization-Associated Signaling Pathways}

STAT3 and its induction of downstream IL-10 are critical for macrophage polarization to the M2 phenotype, while STAT1 is necessary for M1 polarization (Wilson, 2014). The hepatitis $\mathrm{C}$ virus E2 protein increases IL-10 expression in macrophages, promoting macrophage polarization toward the M2 phenotype (Kwon et al., 2019). Mechanistically, the E2 protein inhibits the activation of STAT1 and increases the phosphorylation of STAT3 through reducing the phosphorylation level of SOCS3, thus promoting the transcription of IL-10 and M2 macrophage polarization. Similarly, the infection of severe fever with thrombocytopenia syndrome virus (SFTSV) drives macrophage polarization toward the M2 phenotype to facilitate its efficient replication through upregulating miR-146b by the nonstructural protein encoded by the S segment (NSs). miR-146b functions by inhibiting the expression and phosphorylation of STAT1, inducing the macrophage differentiation to the M2 phenotype (Zhang L. et al., 2019). In addition, some viruses, including poxviruses and herpesviruses, encode functional viral IL-10 (vIL10) and enhance viral infections by directly shifting macrophages polarization toward the M2 phenotype (Ouyang et al., 2014).

\section{Inhibition of Nitric Oxide Production in Macrophages}

$\mathrm{NO}$ is a prominent antiviral effector in M1-polarized macrophages through a variety of mechanisms that have been described in section "Production of Reactive Species." Respiratory syncytial virus (RSV) infection results in the increased level of NO that which interferes with viral replication (Kao et al., 2001). However, this antiviral activity can be antagonized by RSV by inducing the constitutive expression of Arg-1, hydrolyzing L-arginine to L-ornithine and urea and suppressing the reactants required for the synthesis of NO (Santiago-Olivares et al., 2019). NO is mainly produced by iNOS2 in macrophages. ASFV A238L is an NF- $\kappa$ B and NFAT inhibitor and suppresses NO production by inhibiting iNOS2 transcription (Granja et al., 2006). Similarly, SeV infection also results in the suppression of $\mathrm{NO}$ production through the downregulation of the expression of iNOS2 (Odkhuu et al., 2014). Mechanistically, the $\mathrm{C}$ protein of SeV blocks the activation of the JAK-STAT signaling pathway, resulting in the inhibition of M1 macrophage polarization and thus iNOS2 transcription.

\section{Decreasing the Production of Proinflammatory Cytokines}

Activated macrophages produce high-level proinflammatory cytokines upon viral infections. The glycoprotein (GP) of Ebola virus (EBOV) can be cleaved by cellular TACE into secreted GP (sGP) (Zhu et al., 2019). Treatment of activated macrophages with sGP inhibits the production of proinflammatory cytokines, such as TNF- $\alpha$ and IL-6 (Bradley et al., 2018). Moreover, the migratory ability of macrophages is impaired by sGP due to the decreased expression of CD11b. Similarly, Rift Valley fever virus (RVFV) productively infects macrophages in humans and suppresses the expression of proinflammatory cytokines (including IFN- $\alpha 2$, IFN- $\beta$, and TNF- $\alpha$ ) by encoding the NSs protein (McElroy and Nichol, 2012).

\section{Suppression of Antigen Presentation by Macrophages}

Antigen presentation by macrophages is critical for activating $\mathrm{T}$ lymphocytes to clear invading viruses, but viruses have developed multiple immune evasion strategies to counteract the antiviral effects. HIV-1 escapes from the killing by $\mathrm{CD}^{+}$cytotoxic $\mathrm{T}$ lymphocytes (CTLs) by encoding the Nef and Gag proteins (Hendricks et al., 2021). Among them, Nef is associated with the regulation of the antigen-presenting ability of macrophages. More specifically, the Nef protein promotes the degradation of MHC-I, reducing its expression of on the cell surface (Schaefer et al., 2008). VACV infection inhibits T-cell priming by decreasing the expression of MHC-II on the cell surface of APCs and the subsequent synthesis of chemokines and cytokines (Rehm et al., 2009). Further study demonstrated that the VACV A35R protein is involved in this inhibition. Mechanistically, the $A 35 R$ protein is localized to endosomes and may impair the processing and presentation of MHC-II-restricted antigens (Rehm et al., 2010). Similarly, the ASFV EP153R protein, which contain a lectin-like domain, decreases the expression of MHCI antigens on the cell surface and interferes with the exocytosis and presentation of antigens in association with MHC-I on the cell surface through its lectin domain, which may result in the inhibition of antiviral responses by CTLs (Hurtado et al., 2011).

Besides these strategies, there may be more evasion mechanisms that remain to be uncover. For example, large DNA viruses (such as poxviruses and herpesviruses) may encode several soluble viral proteins to block the MHC molecules even in large abundance on the cell surface to suppress antigen presentation. Furthermore, several viral proteins may be involved in the regulation of glucose metabolism and suppress the antiviral responses of $\mathrm{M} 1$-polarized macrophages by negatively regulating the glycolysis pathway.

\section{EXPLOITATION OF M2 MACROPHAGE POLARIZATION FOR EFFICIENT INFECTION}

In response to the robust antiviral responses induced by M1polarized macrophages, several viruses employ multiple immune escape strategies to overcome these host defenses, while other viruses evolve to skew macrophages to the M2 phenotype (Table 1). The M2-polarized macrophages are characterized by increased expression of marker molecules or impaired antiviral responses, which promote primary or secondary infections.

\section{Exploitation of Surface Markers on M2 Macrophages for Virus Entry}

PRRSV mainly replicates in porcine PAMs, resulting in the polarization of PAMs toward the M2 phenotype characterized by the high-level expression of CD163, which serves as a functional receptor for virus entry (Wang et al., 2017; Su et al., 2021). The viral protein(s) essential for regulating 
macrophage polarization remain(s) unknown, but a study has been implied that PRRSV induces M2-polarized macrophages for efficient growth while simultaneously counteracting the antiviral responses of M1-polarized macrophages (Wang et al., 2017). Similarly, treatment of macrophages with IL-4/IL-13 enhanced the infection of the recombinant vesicular stomatitis virus encoding the EBOV-GP (rVSV/EBOV-GP), and a further study showed that the macrophages were polarized toward the M2a phenotype by IL-4/IL-13 with increased expression of specific intercellular adhesion molecule-3-grabbing non-integrin related gene 3 (SIGNR3), promoting the entry of $\mathrm{rVSV} / \mathrm{EBOV}-\mathrm{GP}$ into the host cells (Rogers et al., 2019).

\section{Enhancement of Co-infections With Viruses and Bacteria}

Viral and bacterial co-infections are often observed in infectious diseases in humans and animals and contribute to the deterioration of the illness, but the underlying mechanisms remain to be investigated. The modulation of macrophage polarization by viruses may play an important role in augmenting infections. RSV infection promotes M2-like macrophage polarization by increasing the expression of growth arrest-specific 6 (Gas6), which interacts with Axl and suppresses the antibacterial responses of macrophages (Shibata et al., 2020). Thus, RSV-infected patients are more susceptible to subsequent pneumococcal infections, which triggers secondary pneumococcal pneumonia. Moreover, the reduced production of IL-18 impairs the antibacterial activity of NK cells and then suppresses the production of IFN- $\gamma, \mathrm{NO}$, and TNF- $\alpha$. In contrast, the capsid protein (Cap) of porcine circovirus type 2 (PCV2) suppresses the expression of interferon regulatory factor 4 (IRF4) by inhibiting the transcription of jumonji domain-containing 3 (JMJD3), thus promoting M1 macrophage polarization and bacterial engulfment (Zhang W. et al., 2021).

In addition to the promotion of bacterial infection by viruses, it is very likely that the infection with one virus can be enhanced by another virus through regulation of macrophage polarization. Therefore, elucidating the mechanisms that mediate secondary viral infections may provide clues to screen functional receptors for virus entry and antiviral drugs.

\section{TREATMENTS OF VIRAL DISEASES BY TARGETING MACROPHAGE POLARIZATION}

M1-polarized macrophages play essential roles in fighting against viral infections. Therefore, chemical reagents or natural compounds that promote macrophage polarization into the M1 phenotype may be utilized for antiviral treatment. For instance, baicalin (a natural compound) inhibits IAV infection by inducing antiviral M1 macrophages and activating the IFN signaling pathway (Li and Wang, 2019; Geng et al., 2020). However, the hyperactivation of macrophages, known as macrophage activation syndrome (MAS), causes aberrant inflammatory responses (or "cytokine storm") and severe illness to the hosts (Mahmudpour et al., 2020). SARS-CoV-2 infection causes excessive inflammation in the lungs and progresses to acute respiratory distress syndrome (ARDS) (Otsuka and Seino, 2020). Thus, anti-inflammatory therapeutics can be used to treat coronavirus disease 2019 (COVID-19) (Napoli et al., 2021). To date, IL-1R antagonists (IL-1RA), IL-6R antagonists (IL-6RA), or anti-inflammatory drugs (tofacitinib) have been used in clinical practice. Regarding the viral diseases engaged by M2 macrophages, the treatments of skewing macrophage polarization to the M1 phenotype or blocking several marker molecules that are utilized by viruses for infection will be potential strategies in the future.

\section{CONCLUDING REMARKS AND PROSPECTS}

In the sophisticated immune system, macrophages are the first line of defense against infection and play important roles in the clearance of viruses, bacteria, and solid tumor cells. Macrophages are polarized into the proinflammatory (M1) or anti-inflammatory (M2) phenotype upon exposure to diverse stimuli. M1 macrophages elicit robust antiviral responses by expressing high-level proinflammatory cytokines, promoting cellular oxidation, and/or inducing the activation of other immune cells. To replicate in macrophages efficiently, viruses have employed various strategies to counteract the antiviral responses elicited by M1 macrophages or to skew macrophage polarization to favor the M2 phenotype associated with impaired immune responses. Moreover, some viruses have evolved to adapt to polarized macrophages and exploit marker molecules for efficient replication.

Despite the importance of macrophage polarization in viral infections, the regulatory mechanisms by viruses, which may be the basis for developing therapies against viral diseases, remain to be further elucidated. The worldwide-spread influenza (in 1918, 1957, 1968, and 2009) and coronavirus (in 2003, 2015, and 2019) pandemics showed that the hyperactivated macrophages-mediated "cytokine storm" can cause severe illness (Tisoncik et al., 2012; Liu et al., 2016; Ryabkova et al., 2021). Elucidating the regulatory mechanisms through which viruses regulate macrophage polarization will contribute to the discovery of therapeutic targets for treating viral diseases.

\section{AUTHOR CONTRIBUTIONS}

SY designed the review and drafted the manuscript. H-JQ and SL supervised the review and made critical revisions to the manuscript. HG edited the manuscript. All authors contributed to the article and approved the submitted version.

\section{FUNDING}

This work was funded by the National Natural Science Foundation of China (Grant Nos. 31902264 and 32072866), the Natural Science Foundation of Heilongjiang Province (Grant No. YQ2020C025), and the National Key R\&D Program of China (Grant No. 2021YFD1800104). 


\section{REFERENCES}

Adusumilli, N. C., Zhang, D., Friedman, J. M., and Friedman, A. J. (2020). Harnessing nitric oxide for preventing, limiting and treating the severe pulmonary consequences of COVID-19. Nitric Oxide 103, 4-8. doi: 10.1016/ j.niox.2020.07.003

Akaberi, D., Krambrich, J., Ling, J., Luni, C., Hedenstierna, G., Järhult, J. D., et al. (2020). Mitigation of the replication of SARS-CoV-2 by nitric oxide in vitro. Redox Biol. 37:101734. doi: 10.1016/j.redox.2020.101734

Arango Duque, G., and Descoteaux, A. (2014). Macrophage cytokines: involvement in immunity and infectious diseases. Front. Immunol. 5:491. doi: 10.3389/ fimmu.2014.00491

Arthur, J. S., and Ley, S. C. (2013). Mitogen-activated protein kinases in innate immunity. Nat. Rev. Immunol. 13, 679-692. doi: 10.1038/nri3495

Bility, M. T., Cheng, L., Zhang, Z., Luan, Y., Li, F., Chi, L., et al. (2014). Hepatitis $B$ virus infection and immunopathogenesis in a humanized mouse model: induction of human-specific liver fibrosis and M2-like macrophages. PLoS Pathog. 10:e1004032. doi: 10.1371/journal.ppat.1004032

Bility, M. T., Nio, K., Li, F., McGivern, D. R., Lemon, S. M., Feeney, E. R., et al. (2016). Chronic hepatitis C infection-induced liver fibrogenesis is associated with M2 macrophage activation. Sci. Rep. 6:39520. doi: 10.1038/srep39520

Biswas, S. K., and Lewis, C. E. (2010). NF- $\mathrm{KB}$ as a central regulator of macrophage function in tumors. J. Leukoc. Biol. 88, 877-884.

Boumaza, A., Gay, L., Mezouar, S., Bestion, E., Diallo, A. B., Michel, M., et al. (2021). Monocytes and macrophages, targets of severe acute respiratory syndrome coronavirus 2: the clue for coronavirus disease 2019 immunoparalysis. J. Infect. Dis. 224, 395-406. doi: 10.1093/infdis/jiab044

Boussiotis, V. A. (2016). Molecular and biochemical aspects of the PD-1 checkpoint pathway. N. Engl. J. Med. 375, 1767-1778. doi: 10.1056/NEJMra1514296

Bradley, J. H., Harrison, A., Corey, A., Gentry, N., and Gregg, R. K. (2018). Ebola virus secreted glycoprotein decreases the antiviral immunity of macrophages in early inflammatory responses. Cell. Immunol. 324, 24-32. doi: 10.1016/j. cellimm.2017.11.009

Burdo, T. H., Walker, J., and Williams, K. C. (2015). Macrophage polarization in AIDS: dynamic interface between antiviral and anti-inflammatory macrophages during acute and chronic infection. J. Clin. Cell. Immunol. 6:333. doi: 10.4172/ 2155-9899.1000333

Cai, J., Qi, Q., Qian, X., Han, J., Zhu, X., Zhang, Q., et al. (2019). The role of PD-1/PD-L1 axis and macrophage in the progression and treatment of cancer. J. Cancer Res. Clin. Oncol. 145, 1377-1385. doi: 10.1007/s00432-019-02879-2

Cameron, C. M., Barrett, J. W., Liu, L., Lucas, A. R., and McFadden, G. (2005). Myxoma virus M141R expresses a viral CD200 (vOX-2) that is responsible for down-regulation of macrophage and T-cell activation in vivo. J. Virol. 79, 6052-6067. doi: 10.1128/JVI.79.10.6052-6067.2005

Camini, F. C., da Silva Caetano, C. C., Almeida, L. T., and de Brito Magalhães, C. L. (2017). Implications of oxidative stress on viral pathogenesis. Arch. Virol. 162, 907-917. doi: 10.1007/s00705-016-3187-y

Castro, R. C., Gonçales, R. A., Zambuzi, F. A., and Frantz, F. G. (2021). Notch signaling pathway in infectious diseases: role in the regulation of immune response. Inflamm. Res. 70, 261-274. doi: 10.1007/s00011-021-01442-5

Chan, G., Bivins-Smith, E. R., Smith, M. S., Smith, P. M., and Yurochko, A. D. (2008). Transcriptome analysis reveals human cytomegalovirus reprograms monocyte differentiation toward an M1 macrophage. J. Immunol. 181, 698-711. doi: 10.4049/jimmunol.181.1.698

Chen, W., Liu, Y., Chen, J., Ma, Y., Song, Y., Cen, Y., et al. (2021). The Notch signaling pathway regulates macrophage polarization in liver diseases. Int. Immunopharmacol. 99:107938. doi: 10.1016/j.intimp.2021.107938

Como, C. N., Pearce, C. M., Cohrs, R. J., and Baird, N. L. (2018). Interleukin-6 and type 1 interferons inhibit varicella zoster virus replication in human neurons. Virology 522, 13-18. doi: 10.1016/j.virol.2018.06.013

Csoma, E., Deli, T., Kónya, J., Csernoch, L., Beck, Z., and Gergely, L. (2006). Human herpesvirus $6 \mathrm{~A}$ decreases the susceptibility of macrophages to R5 variants of human immunodeficiency virus 1: possible role of RANTES and IL-8. Virus Res. 121, 161-168. doi: 10.1016/j.virusres.2006.05.007

Dorrington, M. G., and Fraser, I. (2019). NF-кB signaling in macrophages: dynamics, crosstalk, and signal integration. Front. Immunol. 10:705. doi: 10. 3389/fimmu.2019.00705
Epelman, S., Lavine, K. J., and Randolph, G. J. (2014). Origin and functions of tissue macrophages. Immunity 41, 21-35. doi: 10.1016/j.immuni.2014.06.013

Ferrer, M. F., Thomas, P., López Ortiz, A. O., Errasti, A. E., Charo, N., Romanowski, V., et al. (2019). Junin virus triggers macrophage activation and modulates polarization according to viral strain pathogenicity. Front. Immunol. 10:2499. doi: 10.3389/fimmu.2019.02499

Foster-Cuevas, M., Wright, G. J., Puklavec, M. J., Brown, M. H., and Barclay, A. N. (2004). Human herpesvirus 8 K14 protein mimics CD200 in down-regulating macrophage activation through CD200 receptor. J. Virol. 78, 7667-7676. doi: 10.1128/JVI.78.14.7667-7676.2004

Fujikura, Y., Kudlackova, P., Vokurka, M., Krijt, J., and Melkova, Z. (2009). The effect of nitric oxide on vaccinia virus-encoded ribonucleotide reductase. Nitric Oxide 20, 114-121. doi: 10.1016/j.niox.2008.09.002

Gaudreault, N. N., Madden, D. W., Wilson, W. C., Trujillo, J. D., and Richt, J. A. (2020). African swine fever virus: an emerging DNA arbovirus. Front. Vet. Sci. 7:215. doi: $10.3389 /$ fvets.2020.00215

Geng, P., Zhu, H., Zhou, W., Su, C., Chen, M., Huang, C., et al. (2020). Baicalin inhibits influenza a virus infection via promotion of M1 macrophage polarization. Front. Pharmacol. 11:01298. doi: 10.3389/fphar.2020.01298

Granja, A. G., Sabina, P., Salas, M. L., Fresno, M., and Revilla, Y. (2006). Regulation of inducible nitric oxide synthase expression by viral A238Lmediated inhibition of p65/RelA acetylation and p300 transactivation. J. Virol. 80, 10487-10496. doi: 10.1128/JVI.00862-06

Guerriero, J. L. (2019). Macrophages: their untold story in T cell activation and function. Int. Rev. Cell. Mol. Biol. 342, 73-93. doi: 10.1016/bs.ircmb.2018.07. 001

Guo, M., Ye, L., Yu, T., Han, L., Li, Q., Lou, P., et al. (2020). IL-1 $\beta$ enhances the antiviral effect of IFN- $\alpha$ on HCV replication by negatively modulating ERK2 activation. ACS Infect. Dis. 6, 1708-1718. doi: 10.1021/acsinfecdis.9b00506

Hayat, S., Bianconi, V., Pirro, M., Jaafari, M. R., Hatamipour, M., and Sahebkar, A. (2020). CD47: role in the immune system and application to cancer therapy. Cell. Oncol. 43, 19-30. doi: 10.1007/s13402-019-00469-5

Hendricks, C. M., Cordeiro, T., Gomes, A. P., and Stevenson, M. (2021). The interplay of HIV-1 and macrophages in viral persistence. Front. Microbiol. 12:646447. doi: 10.3389/fmicb.2021.646447

Hunegnaw, R., Mushtaq, Z., Enyindah-Asonye, G., Hoang, T., and Robert-Guroff, M. (2019). Alveolar macrophage dysfunction and increased PD-1 expression during chronic SIV infection of rhesus macaques. Front. Immunol. 10:1537. doi: 10.3389/fimmu.2019.01537

Hurtado, C., Bustos, M. J., Granja, A. G., de León, P., Sabina, P., López-Viñas, E., et al. (2011). The African swine fever virus lectin EP153R modulates the surface membrane expression of MHC class I antigens. Arch. Virol. 156, 219-234. doi: $10.1007 / \mathrm{s} 00705-010-0846-2$

Ivashkiv, L. B. (2018). IFN $\gamma$ : signaling, epigenetics and roles in immunity, metabolism, disease and cancer immunotherapy. Nat. Rev. Immunol. 18, 545558. doi: 10.1038/s41577-018-0029-z

Jeon, S., Rowe, A. M., Carroll, K. L., Harvey, S., and Hendricks, R. L. (2018). PDL1/B7-H1 inhibits viral clearance by macrophages in HSV-1-infected corneas. J. Immunol. 200, 3711-3719. doi: 10.4049/jimmunol.1700417

Kao, Y. J., Piedra, P. A., Larsen, G. L., and Colasurdo, G. N. (2001). Induction and regulation of nitric oxide synthase in airway epithelial cells by respiratory syncytial virus. Am. J. Respir. Crit. Care Med. 163, 532-539. doi: 10.1164/ajrccm. 163.2.9912068

Kotwica-Mojzych, K., Jodłowska-Jẹdrych, B., and Mojzych, M. (2021). CD200:CD200R interactions and their importance in immunoregulation. Int. J. Mol. Sci. 22:1602. doi: 10.3390/ijms22041602

Kuo, T. M., Hu, C. P., Chen, Y. L., Hong, M. H., Jeng, K. S., Liang, C. C., et al. (2009). HBV replication is significantly reduced by IL-6. J. Biomed. Sci. 16:41. doi: 10.1186/1423-0127-16-41

Kwon, Y. C., Meyer, K., Peng, G., Chatterjee, S., Hoft, D. F., and Ray, R. (2019). Hepatitis C virus E2 envelope glycoprotein induces an immunoregulatory phenotype in macrophages. Hepatology 69, 1873-1884. doi: 10.1002/hep.29843

Lane, B. R., Markovitz, D. M., Woodford, N. L., Rochford, R., Strieter, R. M., and Coffey, M. J. (1999). TNF-alpha inhibits HIV-1 replication in peripheral blood monocytes and alveolar macrophages by inducing the production of RANTES and decreasing C-C chemokine receptor 5 (CCR5) expression. J. Immunol. 163, 3653-3661. 
Li, K., Xu, W., Guo, Q., Jiang, Z., Wang, P., Yue, Y., et al. (2009). Differential macrophage polarization in male and female $B A L B / c$ mice infected with coxsackievirus B3 defines susceptibility to viral myocarditis. Circ. Res. 105, 353-364. doi: 10.1161/CIRCRESAHA.109.195230

Li, R., Guo, L., Gu, W., Luo, X., Zhang, J., Xu, Y., et al. (2016). Production of porcine $\mathrm{TNF} \alpha$ by ADAM17-mediated cleavage negatively regulates porcine reproductive and respiratory syndrome virus infection. Immunol. Res. 64, 711-720. doi: 10.1007/s12026-015-8772-8

Li, R., and Wang, L. (2019). Baicalin inhibits influenza virus A replication via activation of type I IFN signaling by reducing miR-146a. Mol. Med. Rep. 20, 5041-5049. doi: 10.3892/mmr.2019.10743

Li, S., Wang, J., He, W. R., Feng, S., Li, Y., Wang, X., et al. (2015). Thioredoxin 2 is a novel E2-interacting protein that inhibits the replication of classical swine fever virus. J. Virol. 89, 8510-8524. doi: 10.1128/JVI.00429-15

Lin, Y., Zhao, J. L., Zheng, Q. J., Jiang, X., Tian, J., Liang, S. Q., et al. (2018). Notch signaling modulates macrophage polarization and phagocytosis through direct suppression of signal regulatory protein $\alpha$ expression. Front. Immunol. 9:1744. doi: 10.3389/fimmu.2018.01744

Liniger, M., Gerber, M., Renzullo, S., García-Nicolás, O., and Ruggli, N. (2021). TNF-mediated inhibition of classical swine fever virus replication is IRF1-, NF-KB- and JAK/STAT signaling-dependent. Viruses 13:2017. doi: 10.3390/ v13102017

Liu, Q., Zhou, Y. H., and Yang, Z. Q. (2016). The cytokine storm of severe influenza and development of immunomodulatory therapy. Cell. Mol. Immunol. 13, 3-10. doi: $10.1038 / \mathrm{cmi} .2015 .74$

Liu, Y. C., Zou, X. B., Chai, Y. F., and Yao, Y. M. (2014). Macrophage polarization in inflammatory diseases. Int. J. Biol. Sci. 10, 520-529. doi: 10.7150/ijbs.8879

Ma, C. J., Ni, L., Zhang, Y., Zhang, C. L., Wu, X. Y., Atia, A. N., et al. (2011). PD-1 negatively regulates interleukin-12 expression by limiting STAT-1 phosphorylation in monocytes/macrophages during chronic hepatitis $\mathrm{C}$ virus infection. Immunology 132, 421-431. doi: 10.1111/j.1365-2567.2010.03382.x

Mahmudpour, M., Roozbeh, J., Keshavarz, M., Farrokhi, S., and Nabipour, I. (2020). COVID-19 cytokine storm: the anger of inflammation. Cytokine 133:155151. doi: 10.1016/j.cyto.2020.155151

Marvin, S. A., Russier, M., Huerta, C. T., Russell, C. J., and Schultz-Cherry, S. (2017). Influenza virus overcomes cellular blocks to productively replicate, impacting macrophage function. J. Virol. 91:e01417-16. doi: 10.1128/JVI. 01417-16

Masujin, K., Kitamura, T., Kameyama, K. I., Okadera, K., Nishi, T., Takenouchi, T., et al. (2021). An immortalized porcine macrophage cell line competent for the isolation of African swine fever virus. Sci. Rep. 11:4759. doi: 10.1038/s41598021-84237-2

Mattiola, I., Pesant, M., Tentorio, P. F., Molgora, M., Marcenaro, E., Lugli, E., et al. (2015). Priming of human resting NK cells by autologous M1 macrophages via the engagement of IL-1 $\beta$, IFN- $\beta$, and IL-15 pathways. J. Immunol. 195, 2818-2828. doi: 10.4049/jimmunol

McElroy, A. K., and Nichol, S. T. (2012). Rift Valley fever virus inhibits a proinflammatory response in experimentally infected human monocyte derived macrophages and a pro-inflammatory cytokine response may be associated with patient survival during natural infection. Virology 422, 6-12. doi: 10.1016/j. virol.2011.09.023

Mercer, J., and Greber, U. F. (2013). Virus interactions with endocytic pathways in macrophages and dendritic cells. Trends Microbiol. 21, 380-388. doi: 10.1016/j. tim.2013.06.001

Molteni, C. G., Principi, N., and Esposito, S. (2014). Reactive oxygen and nitrogen species during viral infections. Free Radic. Res. 48, 1163-1169. https://doi.org/ 10.3109/10715762.2014.945443

Mulero, M. C., Huxford, T., and Ghosh, G. (2019). NF-кB, ІкB, and IKK: integral components of immune system signaling. Adv. Exp. Med. Biol. 1172, 207-226. doi: 10.1007/978-981-13-9367-9_10

Murata, Y., Kotani, T., Ohnishi, H., and Matozaki, T. (2014). The CD47-SIRP $\alpha$ signaling system: its physiological roles and therapeutic application. J. Biochem. 155, 335-344. doi: 10.1093/jb/mvu017

Murray, P. J. (2017). Macrophage polarization. Annu. Rev. Physiol. 79, 541-566. doi: 10.1146/annurev-physiol-022516-034339

Napoli, C., Benincasa, G., Criscuolo, C., Faenza, M., Liberato, C., and Rusciano, M. (2021). Immune reactivity during COVID-19: implications for treatment. Immunol. Lett. 231, 28-34. doi: 10.1016/j.imlet.2021.01.001
Nikitina, E., Larionova, I., Choinzonov, E., and Kzhyshkowska, J. (2018). Monocytes and macrophages as viral targets and reservoirs. Int. J. Mol. Sci. 19:2821. doi: 10.3390/ijms19092821

Ocaña-Guzman, R., Torre-Bouscoulet, L., and Sada-Ovalle, I. (2016). TIM-3 regulates distinct functions in macrophages. Front. Immunol. 7:229. doi: 10. 3389/fimmu.2016.00229

Ocaña-Guzman, R., Vázquez-Bolaños, L., and Sada-Ovalle, I. (2018). Receptors that inhibit macrophage activation: mechanisms and signals of regulation and tolerance. J. Immunol. Res. 2018:8695157. doi: 10.1155/2018/8695157

Odkhuu, E., Komatsu, T., Naiki, Y., Koide, N., and Yokochi, T. (2014). Sendai virus $\mathrm{C}$ protein inhibits lipopolysaccharide-induced nitric oxide production through impairing interferon- $\beta$ signaling. Int. Immunopharmacol. 23, 267-272.

Otsuka, R., and Seino, K. I. (2020). Macrophage activation syndrome and COVID19. Inflamm. Regen. 40:19. doi: 10.1186/s41232-020-00131-w

Ouyang, P., Rakus, K., van Beurden, S. J., Westphal, A. H., Davison, A. J., Gatherer, D., et al. (2014). IL-10 encoded by viruses: a remarkable example of independent acquisition of a cellular gene by viruses and its subsequent evolution in the viral genome. J. Gen. Virol. 95, 245-262. doi: 10.1099/vir.0.058966-0

Pant, K., Chandrasekaran, A., Chang, C. J., Vageesh, A., Popkov, A. J., and Weinberg, J. B. (2020). Effects of tumor necrosis factor on viral replication and pulmonary inflammation during acute mouse adenovirus type 1 respiratory infection. Virology 547, 12-19. doi: 10.1016/j.virol.2020.05 .004

Rehm, K. E., Connor, R. F., Jones, G. J., Yimbu, K., Mannie, M. D., and Roper, R. L. (2009). Vaccinia virus decreases major histocompatibility complex (MHC) class II antigen presentation, T-cell priming, and peptide association with MHC class II. Immunology 128, 381-392. doi: 10.1111/j.1365-2567.2009. 03120.x

Rehm, K. E., Connor, R. F., Jones, G. J., Yimbu, K., and Roper, R. L. (2010). Vaccinia virus A35R inhibits MHC class II antigen presentation. Virology 397, 176-186. doi: 10.1016/j.virol.2009.11.008

Rendra, E., Riabov, V., Mossel, D. M., Sevastyanova, T., Harmsen, M. C., and Kzhyshkowska, J. (2019). Reactive oxygen species (ROS) in macrophage activation and function in diabetes. Immunobiology 224, 242-253. doi: 10.1016/ j.imbio.2018.11.010

Ricciardolo, F., Bertolini, F., Carriero, V., and Högman, M. (2020). Nitric oxide’s physiologic effects and potential as a therapeutic agent against COVID-19. J. Breath Res. 15:014001. doi: 10.1088/1752-7163/abc302

Rogers, K. J., Brunton, B., Mallinger, L., Bohan, D., Sevcik, K. M., Chen, J., et al. (2019). IL-4/IL-13 polarization of macrophages enhances Ebola virus glycoprotein-dependent infection. PLoS Negl. Trop. Dis. 13:e0007819. doi: 10. 1371/journal.pntd.0007819

Ryabkova, V. A., Churilov, L. P., and Shoenfeld, Y. (2021). Influenza infection, SARS, MERS and COVID-19: cytokine storm - the common denominator and the lessons to be learned. Clin. Immunol. 223:108652.

Sánchez, E. G., Pérez-Núñez, D., and Revilla, Y. (2017). Mechanisms of entry and endosomal pathway of African swine fever virus. Vaccines 5:42. doi: 10.3390/ vaccines 5040042

Sang, Y., Miller, L. C., and Blecha, F. (2015). Macrophage polarization in virus-host interactions. J. Clin. Cell. Immunol. 6:311. doi: 10.4172/2155-9899.1000311

Santiago-Olivares, C., Rivera-Toledo, E., and Gómez, B. (2019). Nitric oxide production is downregulated during respiratory syncytial virus persistence by constitutive expression of arginase 1. Arch. Virol. 164, 2231-2241. doi: 10.1007/ s00705-019-04259-0

Schaefer, M. R., Wonderlich, E. R., Roeth, J. F., Leonard, J. A., and Collins, K. L. (2008). HIV-1 Nef targets MHC-I and CD4 for degradation via a final common beta-COP-dependent pathway in T cells. PLoS Pathog. 4:e1000131. doi: 10.1371/journal.ppat.1000131

Schneemann, M., and Schoedon, G. (2002). Species differences in macrophage NO production are important. Nat. Immunol. 3:102. doi: 10.1038/ni0202-102a

Sebastian, R., Sravanthi, M., Umapathi, V., Krishnaswamy, N., Priyanka, M., Dechamma, H. J., et al. (2020). Foot-and-mouth disease virus undergoes non-progressive replication in mice peritoneal macrophages and induces M1 polarization. Virus Res. 281:197906. doi: 10.1016/j.virusres

Shapouri-Moghaddam, A., Mohammadian, S., Vazini, H., Taghadosi, M., Esmaeili, S. A., Mardani, F., et al. (2018). Macrophage plasticity, polarization, and function in health and disease. J. Cell. Physiol. 233, 6425-6440. doi: 10.1002/ jcp. 26429 
Shibata, T., Makino, A., Ogata, R., Nakamura, S., Ito, T., Nagata, K., et al. (2020). Respiratory syncytial virus infection exacerbates pneumococcal pneumonia via Gas6/Axl-mediated macrophage polarization. J. Clin. Invest. 130, 3021-3037. doi: 10.1172/JCI125505

Stone, A., Green, R., Wilkins, C., Hemann, E. A., and Gale, M. Jr. (2019). RIG-I-like receptors direct inflammatory macrophage polarization against West Nile virus infection. Nat. Commun. 10:3649. doi: 10.1038/s41467-019-11250-5

$\mathrm{Su}$, C. M., Rowland, R., and Yoo, D. (2021). Recent advances in PRRS virus receptors and the targeting of receptor-ligand for control. Vaccines 9:354. doi: 10.3390/vaccines 9040354

Tatoyan, M. R., Izmailyan, R. A., Semerjyan, A. B., Karalyan, N. Y., Sahakyan, C. T., Mkrtchyan, G. L., et al. (2020). Patterns of alveolar macrophage activation upon attenuated and virulent African swine fever viruses in vitro. Comp. Immunol. Microbiol. Infect. Dis. 72:101513. doi: 10.1016/j.cimid.2020. 101513

Tisoncik, J. R., Korth, M. J., Simmons, C. P., Farrar, J., Martin, T. R., and Katze, M. G. (2012). Into the eye of the cytokine storm. Microbiol. Mol. Biol. Rev. 76, 16-32. doi: 10.1128/MMBR.05015-11

Uehara, E. U., Shida, B., and de Brito, C. A. (2015). Role of nitric oxide in immune responses against viruses: beyond microbicidal activity. Inflamm. Res. 64, 845-852. doi: 10.1007/s00011-015-0857-2

Van Campen, H. (1994). Influenza A virus replication is inhibited by tumor necrosis factor-alpha in vitro. Arch. Virol. 136, 439-446. doi: 10.1007/ BF01321073

Van den Bossche, J., O’Neill, L. A., and Menon, D. (2017). Macrophage immunometabolism: where are we (going)? Trends Immunol. 38, 395-406. doi: 10.1016/j.it.2017.03.001

Wang, L., Hu, S., Liu, Q., Li, Y., Xu, L., Zhang, Z., et al. (2017). Porcine alveolar macrophage polarization is involved in inhibition of porcine reproductive and respiratory syndrome virus (PRRSV) replication. J. Vet. Med. Sci. 79, 1906-1915. doi: 10.1292/jvms.17-0258

Wang, L. X., Zhang, S. X., Wu, H. J., Rong, X. L., and Guo, J. (2019). M2b macrophage polarization and its roles in diseases. J. Leukoc. Biol. 106, 345-358. doi: 10.1002/JLB.3RU1018-378RR

Wang, Y., Fan, K. T., Li, J. M., and Waller, E. K. (2012). The regulation and activity of interleukin-12. Front. Biosci. 4:888-899. doi: 10.2741 /s306

Wilson, H. M. (2014). SOCS proteins in macrophage polarization and function. Front. Immunol. 5:357. doi: 10.3389/fimmu.201 4.00357

Wolf, Y., Anderson, A. C., and Kuchroo, V. K. (2020). TIM3 comes of age as an inhibitory receptor. Nat. Rev. Immunol. 20, 173-185. doi: 10.1038/s41577-0190224-6

Xia, Y., Li, Y., Wu, X., Zhang, Q., Chen, S., Ma, X., et al. (2021). Ironing out the details: how iron orchestrates macrophage polarization. Front. Immunol. 12:669566. doi: 10.3389/fimmu.2021.669566

Yan, J., and Horng, T. (2020). Lipid metabolism in regulation of macrophage functions. Trends Cell Biol. 30, 979-989. doi: 10.1016/j.tcb.2020.09.006

Yang, Y., Kim, S. C., Yu, T., Yi, Y. S., Rhee, M. H., Sung, G. H., et al. (2014). Functional roles of p38 mitogen-activated protein kinase in macrophagemediated inflammatory responses. Mediators Inflamm. 2014:352371. doi: 10. $1155 / 2014 / 352371$

Yao, A., Liu, F., Chen, K., Tang, L., Liu, L., Zhang, K., et al. (2014). Programmed death 1 deficiency induces the polarization of macrophages/microglia to the M1 phenotype after spinal cord injury in mice. Neurotherapeutics 11, 636-650. doi: 10.1007/s13311-013-0254-x
Zelnickova, P., Matiasovic, J., Pavlova, B., Kudlackova, H., Kovaru, F., and Faldyna, M. (2008). Quantitative nitric oxide production by rat, bovine and porcine macrophages. Nitric Oxide 19, 36-41. doi: 10.1016/j.niox.2008.04.001

Zhang, B., Miao, T., Shen, X., Bao, L., Zhang, C., Yan, C., et al. (2020). EB virus-induced ATR activation accelerates nasopharyngeal carcinoma growth via M2-type macrophages polarization. Cell Death Dis. 11:742. doi: 10.1038/ s41419-020-02925-9

Zhang, L., Fu, Y., Wang, H., Guan, Y., Zhu, W., Guo, M., et al. (2019). Severe fever with thrombocytopenia syndrome virus-induced macrophage differentiation is regulated by miR-146. Front. Immunol. 10:1095. doi: 10.3389/fimmu.2019. 01095

Zhang, L., Stanford, M., Liu, J., Barrett, C., Jiang, L., Barclay, A. N., et al. (2009). Inhibition of macrophage activation by the myxoma virus M141 protein (vCD200). J. Virol. 83, 9602-9607. doi: 10.1128/JVI.01078-09

Zhang, N., Bao, Y. J., Tong, A. H., Zuyderduyn, S., Bader, G. D., Malik Peiris, J. S., et al. (2018). Whole transcriptome analysis reveals differential gene expression profile reflecting macrophage polarization in response to influenza A H5N1 virus infection. BMC Med. Genomics 11:20. doi: 10.1186/s12920-018-0335-0

Zhang, Q., Wang, J., Yadav, D. K., Bai, X., and Liang, T. (2021). Glucose metabolism: the metabolic signature of tumor associated macrophage. Front. Immunol. 12:702580. doi: 10.3389/fimmu.2021.702580

Zhang, W., Fu, Z., Yin, H., Han, Q., Fan, W., Wang, F., et al. (2021). Macrophage polarization modulated by porcine circovirus type 2 facilitates bacterial coinfection. Front. Immunol. 12:688294. doi: 10.3389/fimmu.2021.688294

Zhang, W., Huang, Q., Xiao, W., Zhao, Y., Pi, J., Xu, H., et al. (2020). Advances in anti-tumor treatments targeting the CD47/SIRP $\alpha$ axis. Front. Immunol. 11:18. doi: 10.3389/fimmu.2020.00018

Zhang, W., Zhang, Y., He, Y., Wang, X., and Fang, Q. (2019). Lipopolysaccharide mediates time-dependent macrophage M1/M2 polarization through the TIM3/Galectin-9 signaling pathway. Exp. Cell Res. 376, 124-132. doi: 10.1016/j. yexcr.2019.02.007

Zhao, L., Yu, G., Han, Q., Cui, C., and Zhang, B. (2020). TIM-3: an emerging target in the liver diseases. Scand. J. Immunol. 91:e12825. doi: 10.1111/sji.12825

Zhu, W., Banadyga, L., Emeterio, K., Wong, G., and Qiu, X. (2019). The roles of Ebola virus soluble glycoprotein in replication, pathogenesis, and countermeasure development. Viruses 11:999. doi: 10.3390/v11110999

Zwirner, N. W., Domaica, C. I., and Fuertes, M. B. (2021). Regulatory functions of NK cells during infections and cancer. J. Leukoc. Biol. 109, 185-194. doi: 10.1002/JLB.3MR0820-685R

Conflict of Interest: The authors declare that the research was conducted in the absence of any commercial or financial relationships that could be construed as a potential conflict of interest.

Publisher's Note: All claims expressed in this article are solely those of the authors and do not necessarily represent those of their affiliated organizations, or those of the publisher, the editors and the reviewers. Any product that may be evaluated in this article, or claim that may be made by its manufacturer, is not guaranteed or endorsed by the publisher.

Copyright (C) $2022 \mathrm{Yu}, \mathrm{Ge}, \mathrm{Li}$ and Qiu. This is an open-access article distributed under the terms of the Creative Commons Attribution License (CC BY). The use, distribution or reproduction in other forums is permitted, provided the original author(s) and the copyright owner(s) are credited and that the original publication in this journal is cited, in accordance with accepted academic practice. No use, distribution or reproduction is permitted which does not comply with these terms. 